\title{
インタネットで個人放送局を開くには(3)
}

インタネット上で個人放送局を開設するための技術解説を行う。今回は実際のストリーミングソフトウェアを 用いた放送局の開設方法について説明する。

\section{4. ストリーミングソフトウェアの設定と運用}

\section{1 準 備}

2台のPCを用いたインタネット放送局の構成例を図1(a)に 示す．撮影用PCは，カメラとマイクを用いてAVデータをキ ヤプチャして圧縮する. あるいは, 別途撮影したAVファイル を圧縮する．ライブの場合は，圧縮データを即座にパケット 化してサーバに転送し，オンデマンドの場合は，オフライン で圧縮ファイルをサーバに転送する。それぞれの場合に対応 して，サーバPCはストリーミングを実行する。

小人数の視聴者を対象とする場合, 図1(b)のように，キャ プチャから放送までを1台のPCで行うことも可能である.一方， 不特定多数の視聴者を対象とする場合には, 図1(c)に示すよ うに，撮影用PC，ストリームサーバ，WWWサーバ，ファイ アウォール等に複数台のマシンを設置する.さらに，それぞ れのサーバ自身を複数台用意してクラスタ化すれば，負荷分 散の効果が得られる.

撮影用PCの場合, 基本的にPC, ビデオキャプチャカード, サウンドカード，カメラ，マイク等を一式揃える。あるいは， 最近はPCのAV対応が進み, 初めからすべてのインタフェー スが組み込まれている場合も多い.アナログのNTSC入力，あ るいはディジタルのDV入力が備わっていることを確認し，イ ンターフェースに合わせてカメラ, VTR等の機器を購入する. オペレーティングシステムは好みに応じて選択する，ただ し, キャプチャカードに添付されるドライバは，通常は Windows専用である.よってUNIX系の場合は，インタネット 上から別途ドライバを組み込み, カーネルを再構築するのが 普通である，さらにUNIX系では，新製品ほどドライバが提供 されない場合が多い（つまり，キャプチャできない)，よって， UNIX系の場合は，あらかじめ下調べを行った上で機器を揃え

†早稲田大学 理工学部電子. 情報通信学科

"How to Open Personal Broadcasting System on the Internet (3)" by Jiro Katto (Department of Electronics, Information and Communication Engineering, School of Science and Engineering, WASEDA University, Tokyo)

$810 \quad(30)$

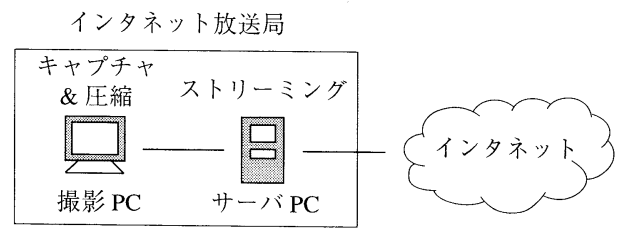

(a) 一般的な構成

キャプチャ\&圧縮 \&ストリーミング

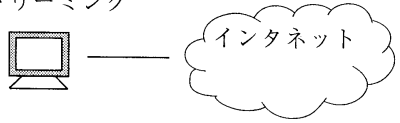

(b) 小規模な構成

インタネット放送局

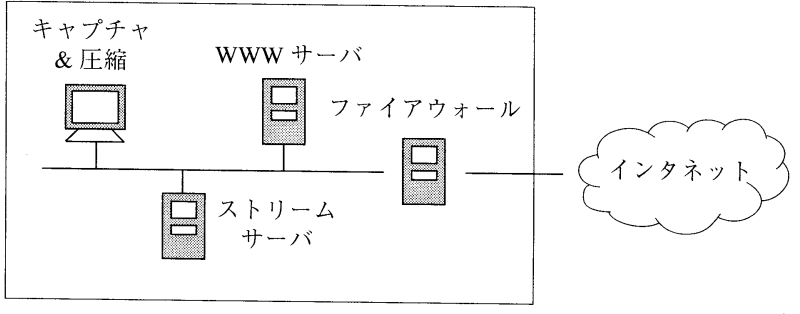

(c) 大規模な構成

図 1 インタネット放送局の構成例

ることが望ましい.

あるいは，最近はカメラとオペレーティングシステム，ネ ットワークが一体化された製品も販売されている（webcam 等). 使用用途は小人数のインタネット放送に限定されるが, 機器のIPアドレスを設定すればすべての設定が完了する.

これに対してサーバPCでは，一般的に周辺機器は不要であ るが, ファイアウォールの設定や各種のネットワーク設定が 重要になる。また，次節で詳しく述べるように，通常のWeb サーバを用いる場合と，インタネット放送用に専用のサーバ ソフトウェアを導入する場合の2通りがある。前者の場合， Apache等のWebサーバを起動するだけだが，パフォーマンス としては当然後者に劣る，後者の場合，Windowsでは2000 
Serverを使用する。これは，Windows 2000 Serverには予めサ 一バソフトウェアが組达まれているからである. UNIX系の場 合, 基本的にはオペレーテイングシステムの制約はないが, 選定したサーバソフトウェアの動作は確認する必要がある.

\subsection{2種類のストリーミング方式}

用意するサーバに応じて，2通りのストリーミング方式が提 供される。

\section{・HTTPストリーミング}

・専用プロトコルを用いたストリーミング

前者は，通常のWeb（HTTP） サーバにストリーミングを行 わせる方式であり，HTTPストリーミングとも呼ばれる。この 場合，撮影用PCと通常のWebサーバを用意するだけで放送局 の開設は完了し，手間はまったくかからない。ただし，専用 サーバ方式に比べるとパフォーマンスは低下し，視聴者数の 限られた小規模な運用に限られる。また，前述のネットワー ク一体型カメラは，一般的にHTTPストリーミングを行うもの である。

これに対して，後者はストリーミング専用の制御プロトコ ルを使用する。具体的な制御プロトコルとしては，リアルネ ットワークス社はRTSP (Real Time Streaming Protocol) と PNA (Progressive Networks Audio), マイクロソフト社は MMS (Microsoft Media Server protocol), アップル社はRTSP を使用している。第1回に説明したように，RTSPはIETFで標 準化されたプロトコルである（RFC 2326）。また，RTSPの 作成には，リアルネットワークス社が深く関与している。一 方, PNAとMMSは, リアルネットワーク社とマイクロソフト 社の独自 (非標準) プロトコルである. ストリーミング専用 のプロトコルを使うことで，送信レート制御やマルチキャス ト，スプリッタ，トリックモード等に柔軟に対応でき，優れ た特性を実現できる。

図2には，HTTPストリーミングと専用プロトコルを用いた ストリーミング方式の違いを示す。共に, 初めはWebページ を介して番組をアナウンスする，視聴者が放送の開始を求め てリンクをクリックすると (1)) , Webサーバが応答して小さ なファイルを返す (2))。このファイルはメタファイルと呼ば れ，Webブラウザはメタファイルを受け取るとビューアソフ トウェアを起動する (3))。ここまでの手順は, HTTPストリ ーミング，専用プロトコルの場合，共にまったく同じである. ただし，(4)以降の手順が異なり，HTTPストリーミングの場 合は，Webサーバが通常のファイル転送と同じ方法（つまり TCP）でストリームファイルを転送する（このために，ビュ ーアもHTTPで会話できるようになっている).これに対して， 専用プロトコルを用いる場合は，ストリームサーバが接続状 況に応じて転送プロトコルや転送レートを決定し，視聴者に 最適な方法でパケットを転送する。いずれの場合も，ビュー アはパケットを受け取りながら復号・再生を繰り返し，スト リーミング再生を実現する。

ありがちなのが，メタファイルを指定しないで，ホームペ

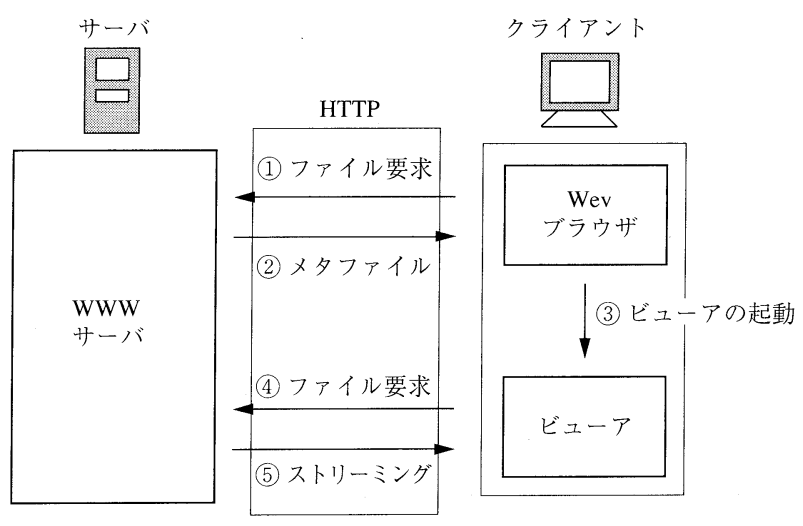

(a) HTTP ストリーミング

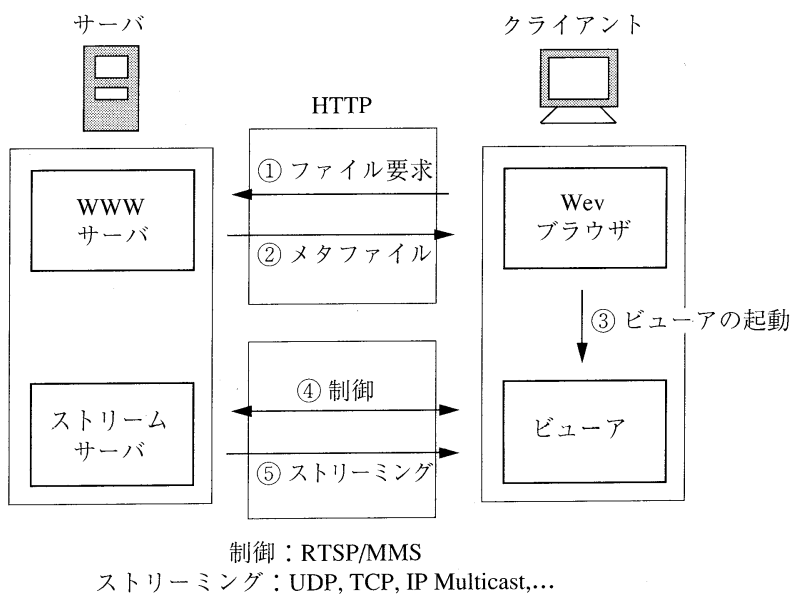

（b）専用プロトコルを用いたストリーミング

図2ＨＨTPストリーミングと専用プロトコルを用いたストリーミング

ージから直接ストリームファイルヘのリンクを貼ってしまう ミスである。この場合，ストリーミングは行われず，ファイ ルのダウンロード後にビューアが起動されることが多い. よ って，ホームページにはメタファイルヘのリンクを記述し， さらにメタファイルにはストリームファイルヘのリンクを記 述する。こうすると，ビューアが起動されてからストリーミ ングが実行される。ただし，サーバには，あらかじめストリ 一ムファイル，メタファイル双方のMIMEタイプを登録して おくことが必要である.

以下に，ストリーミングソフトウェアの代表例として，リ アルネットワークス社のRealSystem ${ }^{1)}$, マイクロソフト社の Windows Media Technologies ${ }^{2)}$, アップル社の QuickTime ${ }^{3)}$ について説明を行う。表1には，各社のストリームファイルと メタファイルのMIMEタイプ一覧を示しておく.

\subsection{RealSystem ${ }^{11}$}

リアルネットワーク社のストリーミングソフトウェア群は RealSystemと呼ばれる.世界中でもっとも利用者が多いこと でも有名である。表2に RealSystemのソフトウェアの一覧を 示す.

4.3.1 エンコーダ

AVデータのキャプチャと圧縮にはReal Producerを使用す 
表 1 MIMEタイプ一覧

\begin{tabular}{c|l}
\hline \hline \multicolumn{1}{c|}{ 名称 } & \multicolumn{1}{c}{ MIME タイプ } \\
\hline \multirow{3}{*}{ RealSystem } & $\begin{array}{l}\text { audio/vnd.m-realmedia rm } \\
\text { application/smil smi smil } \\
\text { audio/x-pn-realaudio ram } \\
\text { audio/x-pn/realaudio-plugin rpm }\end{array}$ \\
\hline \multirow{3}{*}{ Media Technologies } & video/x-ms-wmv wmv \\
& audio/x-ms-wma wma \\
& video/x-ms-asf asf asx \\
\hline QuickTime & video/quicktime mov qt \\
\hline
\end{tabular}

る. 機能限定されたRealProducer Basicは無料で, Real一 Producer Plusは有償で配布されている. ライブキャプチャと ファイル入力が可能であり，ファイルは avi，.movを始め, 多種多様なフォーマットに対応している. 圧縮ファイルは.rm の拡張子が付けられる。 また，圧縮時に複数のレートを選択 することが可能である.このとき, SureStreamオプションを 選択すると，生成されるのは一つの.rmファイルだけだが， RTSPストリーミング時にスケーラブルな転送レート制御が可 能となる（つまり，スケーラビリティを一つのファイルで実 現している). さらに, RTSPサーバ経由のライブ放送も可能 である。

\subsection{2 プレゼンテーション記述とメタファイル}

プレゼンテーション記述は, 特にリアルネットワークス社 からの専用エディ夕は提供されておらず, 通常のエディ夕を 用いてSMIL記述を行う。このとき,ファイル拡張子は.smi とする。ただし，SMILはそれほど複雑な記述言語ではなく， 多くの場合, 不便は感じない. メタファイルは, 通常のエデ イ夕を使って記述するか, あるいは後述するRealSystem Serverのramgenを使って自動生成する.ファイル拡張子は, ヘルパーとして起動する場合は .ram, プラグインとしてWeb ページに埋め込む場合は.rpmとする，共に中身は同じである.

SMILファイルとメタファイルの間には密接な関係がある. 後述するASXファイルのように，SMILファイル自体をメタフ アイルと考えても構わない. 具体的には, HTTPストリーミン グとRTSPストリーミングのどちらを使うかに応じて，メタフ
アイルを以下のように書き分ける.

(1) HTTPストリーミングの.ram ファイル http://web_server/sample.rm

(2) RTSPストリーミングの .ram ファイル rtsp://rtsp_server/sample.rm

ここでweb_serverは実際のWebサーバ名，rtsp_serverは RTSPサーバ名である. rtsp://の替わりに pna://とすれば, リ アルネットワーク社独自の PNA プロトコルが使用される。ま た, .ram ファイルの中で，ストリームファイル .rm を直接参 照する替わりに，.smi 経由で間接参照しても構わない.この 場合，ビューアがまず.smi ファイルを解釈し，その後ストリ 一ム転送が開始される。

さらに, HTTPストリーミングの場合，通常はSureStreamを 使うことはできないが，SMILのswitch文を用いて視聴者の接 続環境に応じた適切なレート選択を行わせる仕組みが用意さ れている.

（3） HTTPストリーミングの.smiファイル

$<$ smil $>$

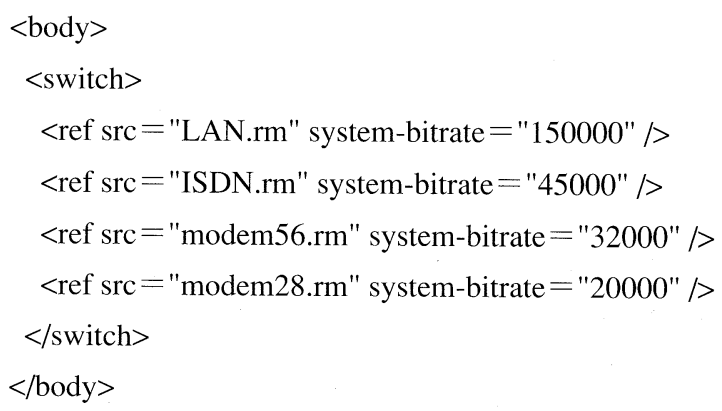

上の例では，あらかじめLAN用 $(150 \mathrm{~kb} / \mathrm{s})$, ISDN用 $(45 \mathrm{~kb} / \mathrm{s}) ， 56 \mathrm{k}$ モデム用 $(32 \mathrm{~kb} / \mathrm{s}) ， 28 \mathrm{k}$ モデム用 $(20 \mathrm{~kb} / \mathrm{s})$ そ れぞれに適したストリームファイルが用意されている。ビュ ーアはSMILファイルを受け取り, 複数のストリームファイル が選択可能であることを知り, 個々の接続環境に応じて適切 な速度のストリームファイルを選択することができる.

最後に，プラグインとしてWebブラウザに埋め达む場合は， HTMLに記述を追加する必要がある，通常のアンカーの替わ

表 2 MIMEタイプ一覧

\begin{tabular}{|c|c|c|}
\hline 目 的 & 名 称 & 入出力フォーマット, プロトコル \\
\hline \multirow{2}{*}{ キャプチャエンコーダ } & \multirow{2}{*}{ Real Producer } & 入力 : ライブ, .avi,.mov 他 \\
\hline & & 出力 : .rm (RealVideo, RealAudio) \\
\hline プレゼンテーション記述 & \multirow{2}{*}{ 各種エディ夕, Ramgen } & ファイル：.smi \\
\hline メタファイル & & メタファイル : .ram \\
\hline \multirow{3}{*}{ ストリームサーバ } & \multirow{3}{*}{ Real System Server } & ファイル：.rm, .smi 他 \\
\hline & & 制御 : RTSP, PNA ${ }^{*}$ \\
\hline & & メディア : RTP, RDT ${ }^{*}$, UDP, TCP, HTTP, IP, Multicast \\
\hline \multirow{2}{*}{ スプリッタプロキシー } & \multirow{2}{*}{ Real System Proxy } & 制御 : RTSP, PNA ${ }^{*}$, HTTP \\
\hline & & メディア : RTP, RDT ${ }^{*}$, UDP, TCP, HTTP, IP, Multicast \\
\hline ビューア & Real Player & 入力 : .rm, .smi, .avi, .mov, .mpg 他 \\
\hline
\end{tabular}


表 3 RealSystem Serverの使用するポート番号

\begin{tabular}{c|c}
\hline \hline RTSP & 554 \\
\hline PNA & 7070 \\
\hline HTTP & 8080 \\
\hline Monitor & 9090 \\
\hline Admin & 16347 \\
\hline
\end{tabular}

りに，例えば以下のようにする。

(4) プラグインのためのHTML記述 $<$ embed

width $=180$ height $=120$

src = "http://web_server/sample.rpm"

controls = "imageWindow"

autostart $=$ true

$>$

4.3.3 ストリームサーバ

ストリームサーバにはRealSystem Serverを使用する。これ は各種オペレーティングシステムに対応し，RTSPとPNAをサ ポートしている。サーバソフトウェアは高価であるが，Basic 版であれば，期限付きではあるが無料で試すことができる。 デーモン起動時にポート番号の設定を行い, デフォルトのポ 一ト番号は表3に示すようになっている。

RealSystem Serverでは，上の8080番を，HTTPを用いて各 種の管理文書を閲覧したり，ramgenを用いて.ramファイルを 自動生成したりするのに使用する。後者の場合，ホームペー ジのHTMLに

http://rtsp_server:8080/ramgen/sample.rm

と記述しておくと，アクセス時にsample.rmに対する.ramフ アイルが自動生成され，ビューアに返される。また16367番は, 同じくHTTPを使用し，リモートからサーバ設定するために使 用される。

なお，表に挙げたRDT（Real Data Transport）は，RTPの代 替として使用されるリアルネットワーク社の独自プロトコル である。詳細は不明であるが，RTPとは異なり，パケット廃 㲤発生時にパケットの再送を要求する。RTPでパケット再送 を要求しないのは，低遅延，マルチキャストへの対応も求め られるからであり，目的が少し異なる。

\subsection{4 プロキシとビューア}

RealSystemでは，スプリッタ機能，プロキシ機能を提供す る RealSystem Proxy， キャプションを作成するRealText，プ レゼンテーションを作成するRealPresenter，なども用意され ている．特にRealSystem Proxyはストリームサーバと対話し ながら，スプリッタ，キャッシング，顧客制限（コンテント 保護）などを実現する，ビューアは RealPlayerであり，よく 知られているようにインタネットから無償でダウンロードす ることができる。

\subsection{Windows Media Technologies ${ }^{2)}$}

マイクロソフト社のストリーミングソフトウェア群は
Windows Media Technologiesと呼ばれる。表4にソフトウェア の一覧を示す.

マイクロソフト社のインタネットマルチメディア関係の製 品は, もともとはデスクトップ用途のMediaPlayer, インタネ ット放送向けのNetShow，インタネット電話向けの NetMeeting，の3系統であった。ここ数年の間に，まず MediaPlayerとNetShowがMedia Technologiesとして統合 され，最近ではさらにNetMeetingも含めた統合も検討されて いるという。

\subsection{1 エンコーダ}

AVデータのキャプチャと圧縮にはMedia Encoderを使用す る. Media Encoderは無償で配布されており，ライブキャプチ ヤ,ファイル入力共に可能である。ファイル形式は .avi，.mov を始め，さまざまなフォーマットに対応している. 圧縮ファイルには.wma，.wmvの拡張子が付けられる。前 は .asf が用いられていたが，中身は同じであり，拡張子によ ってオーデイオ，ビデオを明確に区別しているに過ぎない.

圧縮時に複数のレートを選択することが可能で，インテリ ジェント・ストリーミングの使用を前提に, 出力自体は一つ のストリームファイルとすることもできる。これをMMSサー バに置いてストリーミング転送を行うと, RealSystemの SureStremと同様に，スケーラブルな転送レート制御が実行さ れる．また，MMSサーバ経由のライブ放送も可能である.

4.4.2 プレゼンテーション記述とメタファイル プレゼンテーション記述とメタファイルは, Media Technologiesの場合はASXと呼ばれる一つのファイルに統一 されている.ASXファイルの編集用にMetafile Creatorと呼ば れるエディ夕が提供されるが，もちろん通常のエディ夕を使 用してもよい。 また， ASXファイルの拡張子は.asxである.

HTTPストリーミングとMMSストリーミングの使い分けは RealSystemと同様である。web_serverをWebサーバ名， mms_serverをMMSサーバ名とすれば，ASXファイルは以下の ように記述される。

(1) HTTPストリーミングのASXファイル

$<\operatorname{ASX}$ version $=" 3 ">$

$<$ Entry $>$

$<$ ref HREF="http://web_server/sample.wmv" /> $<$ /Entry $>$

$</$ ASX $>$

(2) MMSストリーミングのASXファイル

$<$ ASX version $=" 3 ">$

$<$ Entry $>$

$<$ ref HREF="mms://mms_server/sample.wmv" $>>$

$</$ Entry $>$

$</ \mathrm{ASX}>$

上の例はきわめて基本的な使い方であるが，ASXではこの 他にもさまざまな夕グが定義されており，SMILと同様のコン テント作成が可能である. 


\begin{tabular}{|c|c|c|}
\hline 目 的 & 名 称 & 入出カフォーマット, プロトコル \\
\hline \multirow{2}{*}{ キャプチャエンコーダ } & \multirow{2}{*}{ Media Encoder 等 } & カ :ライブ,.avi,.mov 他 \\
\hline & & 力: .wmv, .wma (WM Video, WM Audio), .asf \\
\hline プレゼンテーション記述 & \multirow{2}{*}{$\begin{array}{l}\text { Metafile Creator 他 } \\
\text { 各種エディタ }\end{array}$} & \multirow{2}{*}{ メタファイル： ask } \\
\hline メタファイル & & \\
\hline \multirow{3}{*}{ ストリームサーバ } & \multirow{3}{*}{ Media Server } & ファイル：.wmv, .wma, .asf 他 \\
\hline & & 制 御 : MMS* \\
\hline & & メディア：RTP, UDP, TCP, HTTP, IP, Multicast \\
\hline コンテント保護 & Media Rights Manager & 独 \\
\hline ビューア & Media Player & 力 : .wmv, .wma, .asf, .avi, .mpg 他 \\
\hline
\end{tabular}

*MMS はマイクロソフト社の独自プロトコル

表 5 QuickTimeのソフトウェア一覧

\begin{tabular}{|c|c|c|}
\hline 目 的 & 名 称 & 入出力フォーマット, プロトコル \\
\hline \multirow{2}{*}{ キャプチャエンコーダ } & \multirow{2}{*}{$\begin{array}{l}\text { QuickTime Pro, } \\
\text { Sorenson, Qdesign 他 }\end{array}$} & 入力 : .mov, .qt 他 \\
\hline & & 出力 : .mov, .qt 他 \\
\hline プレゼンテーション記述 & \multirow{2}{*}{ 各種エディ夕 } & ファイル：.smi \\
\hline メタファイル & & メタファイル：.mov (詳細不明) \\
\hline \multirow{3}{*}{ ストリームサーバ } & \multirow{3}{*}{$\begin{array}{l}\text { QuickTime } \\
\text { Streaming Server }\end{array}$} & ファイル：.mov,.qt. smi 他 \\
\hline & & 制御：RTSP \\
\hline & & メディア：RTP, UDP, TCP, HTTP, IP, Multicast \\
\hline ビューア & QuickTime Player & 入力 : .mov, .mpg 他 \\
\hline
\end{tabular}

Webページに埋め込むプラグインの場合は, 通常のアンカ 一の替わりに，以下の記述をHTMLに追加する.

(3) プラグインのためのHTML記述

$<$ embed

width $=180$ height $=120$

src $=$ "http://web_server/sample.asx"

$>$

4.4 .3 ストリームサーバ

ストリームサーバはMedia Serverを使用する。これは

Windows 2000 Serverにあらかじめ組込まれており，NTの場 合は別途無償で提供される。ストリーミング用プロトコルは マイクロソフト社独自のMMSをサポートする．以前はMSBD (Media Distribution Broadcast Protocol) という独自プロトコ ルも使われたが，最近はほとんど使われなくなっている。

\subsection{4 コンテント保護とビューア}

Media Technologiesでは，コンテント保護のためのMedia Rights Managerを提供している。これは，ストリームファイ ルを暗号化して保護するものであり，技術的な詳細は不明で ある. RealSystemが主にプロキシによってコンテント保護を 図るのに対し，Media Rights ManagerはEnd-to-Endのコンテン 卜保護であり，好対照をなしている。

一方，ビューアはMedia Playerが提供される。これはあらか じめすべてのWindowsファミリに組込まれており，最新版も インタネットを介して随時ダウンロードすることができる.
表 6 RealSystemとQuickTime の相互接続性

\begin{tabular}{c|l}
\hline \hline \multicolumn{1}{|c|}{ 名称 } & \multicolumn{1}{c}{ MIME タイプ } \\
\hline \multirow{2}{*}{ RealSystem } & $\begin{array}{l}\text { audio/vnd.m-realmedia rm } \\
\text { application/smil smi smil } \\
\text { audio/x-pn-realaudio ram } \\
\text { audio/x-pn/realaudio-plugin rpm }\end{array}$ \\
\hline \multirow{2}{*}{ Media Technologies } & $\begin{array}{l}\text { video/x-ms-wmv wmv } \\
\text { audio/x-ms-wma wma } \\
\text { video/x-ms-asf asf asx }\end{array}$ \\
\hline QuickTime & video/quicktime mov qt \\
\hline
\end{tabular}

\subsection{QuickTime ${ }^{3)}$}

アップル社のストリーミングソフトウェア群がQuickTimeで ある. 古くからマッキントッシュ用のマルチメディアソフト として有名だが，最近はとりわけインタネット対応を進めて いる．表5にソフトウェアの一覧を示す.

4.5.1 エンコーダ

AVデータの圧縮にはQuickTime Proを使用する。無償でダ ウンロード可能なQuickTimeに, 有償のライセンスアップグ レードを登録することで動作する。筆者の用いたバージョン (QuickTime 4.1：Windows版）では，ライブキャプチャは できなかった．他のエンコーダと同じく，入力は .avi，.mov を始めさまざまなフォーマットに対応している，出力では， インタネットストリーミング用を指定すると，拡張子が .mov のファイルが一つ生成される。圧縮形式は，ビデオ圧縮用の 
Sorenson Video，オーデイオ圧縮用の QDesign Audio，音声 圧縮用のQualcom PureVoice他，さまざまなソフトウェアが提 供されている。ただし，ライブ放送を行うためには，現状で はSorenson Broadcasterを別途購入しなければならない。

\subsection{2 プレゼンテーション記述とメタファイル}

プレゼンテーション記述には，RealSystemと同じくSMILを 用いることができる。一方, QuickTimeのメタファイル は，ram や .asx のようなテキスト記述ではなく，バイナリ形 式のスクリプトを用いている模様である.

\subsection{3 ストリームサーバ}

ストリームサーバには，QuickTime Streaming Serverを使用 する。これはアップル社のホームページから無償でダウンロ ードすることができる。さらにはオープンプロジェクトとし てソースコードも公開されている。 サポートするプロトコル はRTSPである。ただし，表6に示すように，現状では RealSystem ServerとQuickTime Streaming ServerのRTSPレべ ルの相互接続性は完全には実現されていない。

\section{5 .4 ビューア}

QuickTimeのビューアはQuickTime Playerであり，これはイ ンタネット経由で無償でダウンロードすることができる.

\section{6 総 括}

RealSystemの場合を例に取り，放送局開設のための具体的 な手順をまとめておく，その他のソフトウェアの場合もほぼ 同じ手順である.

（1）エンコード環境とサーバ環境を整える.

（2）キャプチャ入力，もしくはファイル入力からストリー ムファイル sample.rmを作成する.

（3）番組案内用のHTMLファイル sample.html と, メタファ イル sample.ramを作成する.

(4) sample.htmlをWebサーバに, sample.ramと sample.rmを ストリームサーバに，それぞれ保存する。

以上で開局は終了である。視聴者がアクセスしてくると， 4.2 に述べた手順に従ってインタネット放送が開始される。 ス トリームサーバを使わない場合は，HTTPストリーミングが実 行される.

第1回に説明した手順に従えば，RTSPセッションの開始時 に転送されるべきSDPファイルが存在しない.これはミスで はなく, RealSystemとQuickTimeの場合，ストリームサーバ によって自動生成されている。この様子は，Ethereal ${ }^{4)}$ 等のパ ケット解析ツールを用いて観察できる。 RealSystemの .rm, Media Technologiesの .asf, QuickTimeの.qtは，それぞれつ アイルフォーマットとも呼ばれている. rm ファイルの詳細は 不明だが，他の2つは仕様が公開されている（最近のASFは不 明)。共にファイルの先頭に制御ヘッダを配し，圧縮データを 添付してストリームファイルを構成する。上記のSDPファイ ルの自動生成は，この制御へッダに基づいて実行される。制 御ヘッダはまた，圧縮データのディレクトリ管理やRTPパケ
ット生成のヒント等，さまざまな用途に使用される。 QuickTimeの場合，特に後者のヒント情報はヒントトラック と呼ばれ，エンコード時にカスタマイズすることもできる。

一方，これらのシステムは.mpgや.mp3 など，上記のファイ ルフォーマット以外の圧縮ファイルのストリーミングも可能 である。この場合はファイル拡張子や圧縮ファイルのヘッダ 部分の解析結果から，SDPを推測・生成しているものと考え られる，基本的に，固定長フレームを用いる符号化アルゴリ ズム，あるいはユニークワードを挿入する符号化アルゴリズ ムであれば，どのような圧縮ファイルもストリーミング転送 が可能である.

\section{5.おわりに}

以上，インタネット放送に関して，基本的な原理，プロト タイプの作成方法，商用ソフトゥェアの使用方法，について 説明を行った．毎回述べているように，インタネット放送と は数多くの技術の集合体であり，きわめて明確なプロトコル 階層として構成されている.

商用ソフトウェアの現状を見ると，リアルネットワーク社 はネットワークソフトウェアとして, マイクロソフト社とア ップル社はオペレーティングシステムの一部として，インタ ネット放送を位置付けている，インタネット上のマルチメデ イア配信に関してはいまだに賛否両論があるが，やがては $\mathrm{TCP} / \mathrm{IP}$ のうに，なくてはならないプロトコルになるのかも しれない。

インタネット放送の将来を考えた場合, 結局のところ, 各 コンポーネントの発展が望まれる。プロトコル階層の上位か ら順に,

・符号化アルゴリズムの改善

・新しいコンテントの導入 (文献 5) 等)

・品質制御と輻輳制御の協調アルゴリズム

・各種インタネットQoS

・ワイアレス，モビリティ拡張（文献2）等）

等の大局的な発展が期待される.

(2000年11月2日受付)

\section{〔文 献〕}

1) Real Networks: http://www.realnetworks.com

2) Windows Media Technologies: http://www.microsoft.com/ windows/windowsmedia

3) Apple QuickTime: http://www.apple.com/quicktime

4) The Ethereal : http://www.ethereal.com

5) Viewpoint : http://www.viewpoint.com

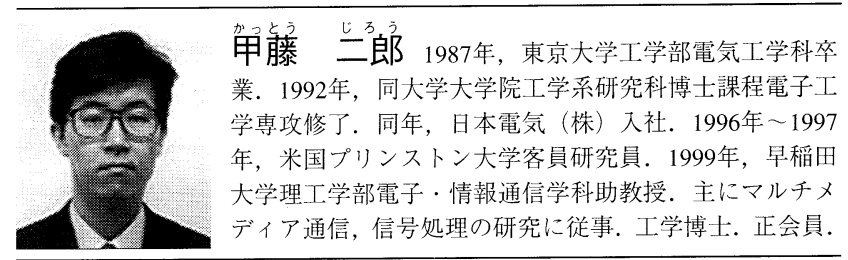

